\title{
Effect of a two-way quality feedback nursing model on patients with chronic obstructive pulmonary disease
}

\author{
Xiaoyan Cai, Yinhua Zhao, Xiaolan Deng, Fang Fang \\ Department of Geriatrics, Nanjing Drum Tower Hospital, the Affiliated Hospital of Nanjing University Medical School, Nanjing, China \\ Contributions: (I) Conception and design: X Cai, F Fang; (II) Administrative support: X Deng; (III) Provision of study materials or patients: X Cai, \\ Y Zhao; (IV) Collection and assembly of data: Y Zhao, X Deng; (V) Data analysis and interpretation: X Cai, F Fang; (VI) Manuscript writing: All \\ authors; (VII) Final approval of manuscript: All authors. \\ Correspondence to: Fang Fang. Master of Nursing, Department of Geriatrics, Nanjing Drum Tower Hospital, the Affiliated Hospital of Nanjing \\ University Medical School, Nanjing, China. Email: fangfang7778@126.com.
}

\begin{abstract}
Background: In recent years, the incidence of chronic obstructive pulmonary disease (COPD) has been increasing gradually, becoming a relatively intractable public health problem faced by all of society. The corresponding conventional nursing interventions are not effective for the rehabilitation of COPD patients and cannot meet clinical needs. In this study, a new nursing model, a two-way quality feedback nursing model, was applied for the treatment of COPD patients.
\end{abstract}

Methods: This retrospective study included 120 moderate COPD patients admitted to our hospital between January 2018 and December 2018, and the patients were equally divided into the experimental group ( $n=60)$ and the control group $(n=60)$ according to the nursing strategy received by patients. The control group received routine nursing care, the two-way quality feedback nursing model was applied in the experimental group, and the nursing effects in the two groups were compared.

Results: The patient compliance of the experimental group to nursing care was $91.67 \%$, that of the control group was $78.33 \%(\mathrm{P}<0.05)$, and the scores for social relationship, environmental impact, psychological condition, and physiological condition of quality of life (QoL) in the experimental group at discharge were higher than those in the control group $(\mathrm{P}<0.05)$.

Conclusions: The application of the two-way quality feedback nursing model in COPD patients could improve patient compliance and significantly improve the QoL of patients, with good application value.

Keywords: Chronic obstructive pulmonary disease (COPD); two-way quality feedback; nursing model; influence

Submitted May 13, 2020. Accepted for publication Sep 11, 2020.

doi: 10.21037/apm-20-1532

View this article at: http://dx.doi.org/10.21037/apm-20-1532

\section{Introduction}

Due to the deterioration of the environment in recent years and the large number of smokers in China, the incidence of chronic obstructive pulmonary disease (COPD) has gradually increased $(1,2)$. COPD mainly affects middle-aged and elderly population, and the main symptoms include coughing, sputum, and dyspnea. In addition, the onset of COPD is insidious, the course of COPD is long, and recurrent attacks of COPD are likely. Currently, there are approximately 600 million patients around the world that are suffering from COPD. This disease causes irreversible damage to the lungs of patients and severely affects their quality of life (QoL). It has been regarded as one of the most difficult public health problems faced by all human beings.

Currently, the clinical treatment principle of COPD is to restore pulmonary ventilation as much as possible, to improve lung inflammation, and to delay the decline in pulmonary function. However, it is still impossible to completely cure COPD as the pulmonary function of the patients decrease progressively. The progressive airflow 
limitation in COPD patients could lead to a decrease in patients' confidence in treatment, resulting in negative emotions, such as irritation, so that patient compliance could be reduced, which has a negative effect on the overall treatment. In this way, a vicious circle can easily form, causing the development of common chronic diseases, such as chronic pulmonale and respiratory failure, and even death or disability in COPD patients if there are no timely interventions $(3,4)$.

It has been widely accepted that the coupling of effective clinical nursing interventions with early diagnosis and medicine therapy have great impact on COPD patients.

Recent studies have reported that high-quality nursing intervention can not only eliminate adverse psychological conditions and maintain a positive attitude toward treatment in COPD patients but also reduce the risk of pulmonary fungal infection to a certain extent (5). The two-way feedback nursing model pays more attention on patients' comments about nursing work and revises the nursing strategy quickly, which helps to establish personalized nursing strategy for individual patient. This model has been widely used in nursing of the cardiopathy and chronic systemic autoimmune disease, whereas its availability remains unrevealed in COPD nursing. In this study, a twoway quality feedback nursing model was adopted for COPD patients to evaluate its clinical value.

We present the following article in accordance with the CONSORT reporting checklist (available at http://dx.doi. org/10.21037/apm-20-1532).

\section{Methods}

\section{Study subjects}

A total of 120 COPD patients admitted to our hospital between January 2018 and December 2018 were included in this study. All patients were diagnosed as moderate COPD $\left(\mathrm{FEV}_{1} / \mathrm{FVC}\right.$ ratio $<70 \%$ and $\left.50 \%<\mathrm{FEV}_{1}<80 \%\right)$. The study was conducted in accordance with the Declaration of Helsinki (as revised in 2013). The study was approved by the Ethics Committee, and each patient signed an informed consent form. The patients were divided into two groups according to the different nursing strategy. There were 60 patients in the experimental group, including 39 men and 21 women, with an average age of $59.28 \pm 8.36$ years old and an age range of 46-69 years old. The disease course was between 1 and 7 years with a mean disease duration of $3.62 \pm 1.18$ years. There were 60 patients in the control group, including 36 men and 24 women, with an average age of $59.59 \pm 8.14$ years old and an age range of $45-71$ years old. The disease course was between 1 and 7 years with an average disease duration of $3.89 \pm 1.21$ years. There were no statistically significant differences in age, sex, or disease duration between the two groups $(\mathrm{P}>0.05)$.

\section{Study methods}

The conventional nursing intervention was implemented in the control group, including condition monitoring, psychological counseling, health education, and instructions about medication, diet, and rest. In the experimental group, a two-way quality feedback nursing model was applied. Based on the patients' comprehension abilities and personality traits, an appropriate communication method was selected, and a good nurse-patient relationship was established through comprehensive communication to improve the sense of security and reduce the anxiety of patients (6). During nursing care, the nursing staff regularly asked the patients about their feelings toward the nursing care and obtained the advice and feedback of the patients for the nursing care. The nursing staff adjusted and improved the nursing care plan based on the patients' feedback. After the improvement, a new nursing model was applied for the patients, and the improved parts were clearly introduced to the patients to strive for patients' understanding and cognition. After the new nursing model was implemented, feedback was obtained from the patients, and improvements were made continually to gradually improve the nursing quality.

\section{Observation indicators}

\section{Patient compliance with nursing}

The nursing staff performed evaluations based on the performance of the patients during hospitalization, including the degree of medication compliance, the degree of rest compliance, and the degree of diet compliance. The evaluation results were as follows: complete compliance, partial compliance, and noncompliance; and patient compliance only included complete compliance and partial compliance.

\section{QoL}

The World Health Organization Quality of Life Scale Abbreviated Version (WHOQOL-BREF) was used at admission and discharge. The evaluation included four 
Table 1 Comparison of patient compliance with nursing between the two groups [ $\mathrm{n}(\%)$ ]

\begin{tabular}{lcccc}
\hline Compliance & Experimental group $(\mathrm{n}=60)$ & Control group $(\mathrm{n}=60)$ & $\chi^{2}$ & - \\
\hline Complete compliance & $22(36.67)$ & $17(28.33)$ & - & - \\
Partial compliance & $33(55.00)$ & $30(50.00)$ & - & - \\
Noncompliance & $5(8.33)$ & $13(21.67)$ & 4.183 & 0.0408 \\
Patient compliance & $55(91.67)$ & $47(78.33)$ & \\
\hline
\end{tabular}

Table 2 Comparison of QoL between the two groups at admission and at discharge $(\bar{x} \pm s$, points)

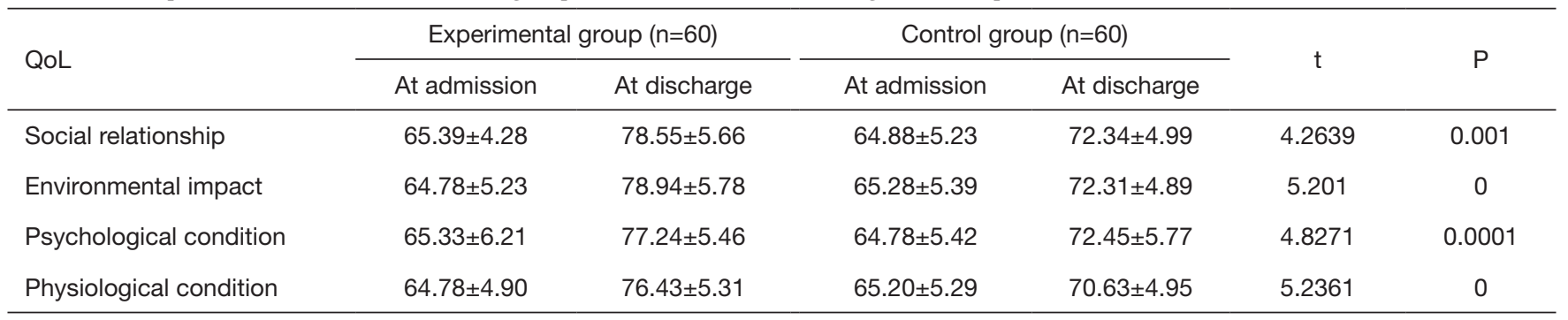

Note: $t$ and $P$ are obtained by the comparisons of scores at discharge.

categories: social relationship, environmental impact, psychological condition, and physiological condition. The maximum score in each category is 100 , and the higher the score is, the better the QoL is (7).

\section{Statistical methods}

SPSS software, version 22.0 (IBM company, United States), was used to analyze the results. The QoL results are expressed as $(\bar{x} \pm s)$, and patient compliance with nursing is expressed as $[\mathrm{n}(\%)]$. The $t$-test and $\chi^{2}$ test were performed, and $\mathrm{P}<0.05$ was considered statistically significant.

\section{Results}

\section{Patient compliance with nursing}

The patient compliance with nursing in the experimental group was $91.67 \%$, which was significantly higher than that in the control group $(78.33 \%, \mathrm{P}<0.05)$ (Table 1).

\section{QoL}

At the time of admission, there were no statistically significant differences in the scores of social relationship, environmental impact, psychological condition, and physiological condition of QoL between the two groups, while at the time of discharge, the scores in the experimental group were significantly higher than that of control group $(\mathrm{P}<0.05)$ (Table 2), suggesting that the twoway quality feedback nursing model can improves the QoL of COPD patients.

\section{Discussion}

Due to the characteristics of COPD itself, such as a protracted and long disease course with recurrent attacks, and the impacts of treatment, disease condition, age, and the education levels of patients, it is difficult to ensure treatment compliance of COPD patients. In particular, the affected population of COPD is mainly elderly people, which are typically poor in education and financial situation with few knowledge about COPD. In some cases, patients prefer to tolerate the symptoms of COPD rather than seek for medical treatment, which results in a relatively long treatment compliance and affect the overall treatment effect $(8,9)$. COPD causes irreversible lung injury, progressive pulmonary dysfunction, and progressive airflow limitation. Even if treatment plays a role in inhibiting the development of COPD, as long as the clinical symptoms do not improve or slightly improve but with recurrence, the patient's confidence in treatment could be greatly reduced. In this way, as the treatment compliance of patients is reduced, the effect of clinical treatment is impacted, the patient's 
condition deteriorates, and a vicious circle emerges. Currently, there are a large number of COPD patients in China with high mortality and disability rates, posing great challenges to the public health of China and a burden to all of society. Therefore, to minimize the mortality and disability rates due to COPD, apart from clinical treatments, the cooperation of nursing staff is also very important. Effective treatment and nursing care promoted the patients to rebuild confidence in treatment and improve treatment compliance to improve clinical symptoms to the greatest extent (10).

To ensure the smooth progression of the treatment and maximize the treatment effect, the corresponding nursing intervention must be implemented. In this study, the experimental group adopted the two-way quality feedback nursing model, and the results showed that, after the intervention, the patient compliance was $91.67 \%$, which was significantly higher than that in the control group $(78.33 \%, \mathrm{P}<0.05)$. In addition, the indicators of $\mathrm{QoL}$ in the experimental group at discharge were significantly higher than those in the control group $(\mathrm{P}<0.05)$, indicating that the nursing intervention under the guidance of the twoway quality feedback nursing model could establish a more harmonious nurse-patient relationship so that patients can comply more with the nursing care. In this manner, the quality of nursing care was improved, and a higher clinical effect was obtained so that the QoL of the patients was significantly improved compared with the conventional nursing model. The closely connection between mental disorders and chronic disease has been widely accepted. Most of the chronic disease patients are suffering from psychological troubles, which have negative effects on the development of the disease. The most important characteristic of the two-way quality feedback nursing model was the emphasis on communication between nurses and patients. Additional attention was paid to obtain opinions from patients about nursing care and feedback from them, and the nursing plan was constantly adjusted according to this patient feedback, making the nursing care constantly in line with the needs of patients; at the same time, the enthusiasm of patients was also mobilized, which played an important role in improving patient compliance (11). Improvement in mental situation will enhance patients' confidence and motivation to overcome the illness and in turn promote the patients to cooperate with treatment actively. Although modification in nursing model can't fully improve the illness, it is helpful to maximize the treatment effect.
A limitation for this experiment is the small samples. To overcome this limitation, we set up strict inclusion criteria. Firstly, we chose the moderate COPD patients with their $\mathrm{FEV}_{1} / \mathrm{FVC}$ ratio $<70 \%$ and $\mathrm{FEV}_{1}$ between $50 \%$ and $80 \%$. Secondly, the average course of the patients is longer than 3 years, suggested that they might endured physical and psychological troubles. We used these standards to reduce the impact of small samples. In the further, we will add more samples to enrich our date.

In summary, the application of the two-way quality feedback nursing model in the care of COPD patients can improve patient compliance and help patients obtain a high QoL, and this model therefore has good application value.

\section{Acknowledgments}

Funding: This work was supported by grant BJ190002 from Jiangsu Commission of health to FF.

\section{Footnote}

Reporting Checklist: The authors have completed the CONSORT reporting checklist. Available at http://dx.doi. org/10.21037/apm-20-1532

Data Sharing Statement: Available at http://dx.doi. org/10.21037/apm-20-1532

Conflicts of Interest: All authors have completed the ICMJE uniform disclosure form (available at http://dx.doi. org/10.21037/apm-20-1532). The authors have no conflicts of interest to declare.

Ethical Statement: The authors are accountable for all aspects of the work in ensuring that questions related to the accuracy or integrity of any part of the work are appropriately investigated and resolved. The study was conducted in accordance with the Declaration of Helsinki (as revised in 2013). The study was approved by the Ethics Committee, and each patient signed an informed consent form.

Open Access Statement: This is an Open Access article distributed in accordance with the Creative Commons Attribution-NonCommercial-NoDerivs 4.0 International License (CC BY-NC-ND 4.0), which permits the noncommercial replication and distribution of the article with the strict proviso that no changes or edits are made and the 
original work is properly cited (including links to both the formal publication through the relevant DOI and the license). See: https://creativecommons.org/licenses/by-nc-nd/4.0/.

\section{References}

1. Huang ZY, Lin S, Long LL, et al. Predicting the morbidity of chronic obstructive pulmonary disease based on multiple locally weighted linear regression model with K-means clustering. Int J Med Inform 2020;139:104141.

2. Cui Y, Dai Z, Luo L, et al. Classification and treatment of chronic obstructive pulmonary disease outpatients in China according to the Global Initiative for Chronic Obstructive Lung Disease (GOLD) 2017: comparison with GOLD 2014. J Thorac Dis 2019;11:1303-15.

3. Gong H. Effect of nursing intervention on rehabilitation compliance of patients with chronic obstructive pulmonary disease. The Medical Forum 2019;23:1212-4.

4. Crisafulli E, Manco A, Torres A. How may we improve clinical outcomes for patients hospitalized with acute exacerbations of chronic obstructive pulmonary disease? A narrative review about possible therapeutic and preventive strategies. Expert Rev Respir Med 2020;14:493-500.

5. Zhang Y. Effect of high-quality nursing intervention on mental state and occurrence of pulmonary fungal infection in patients with chronic obstructive pulmonary disease. The Journal of Medical Theory of Practice

Cite this article as: Cai X, Zhao Y, Deng X, Fang F. Effect of a two-way quality feedback nursing model on patients with chronic obstructive pulmonary disease. Ann Palliat Med 2020;9(5):3182-3186. doi: 10.21037/apm-20-1532
2020;33:1513-4.

6. Guo M. Meticulous nursing to improve the adverse psychological stress of chronic obstructive pulmonary disease patients under acute attack. Chronic Pathematology Journal 2019;20:124-6.

7. Yan L. Effect of comprehensive nursing intervention on quality of life and lung function of elderly patients with stable chronic obstructive pulmonary disease. Chinese Journal of Modern Drug Application 2019;13:190-1.

8. Zhao X. Effect of targeted rehabilitation nursing on chronic obstructive pulmonary disease patients with pulmonary respiratory failure. Medical Journal of Chinese People's Health 2019;31:143-5.

9. Guo J, Chen Y, Zhang W, et al. Moderate and severe exacerbations have a significant impact on health-related quality of life, utility, and lung function in patients with chronic obstructive pulmonary disease: A meta-analysis. Int J Surg 2020;78:28-35.

10. Liao J. A brief analysis of the effect of clinical nursing intervention and its impact on the quality of life on the elderly patients with chronic obstructive pulmonary disease. Chinese and Foreign Medical Research 2019;17:80-1.

11. Lin M. Effect of chronic disease management on quality of life in patients with stable chronic obstructive pulmonary disease. Chinese Journal of Geriatric Care 2019;17:135-6. 